\title{
Training young engineers to see
}

\author{
Göran Backlund · Jan Sjunnesson
}

Received: 20 August 2011/Accepted: 7 November 2011/Published online: 29 November 2011

(C) The Author(s) 2011. This article is published with open access at Springerlink.com

\begin{abstract}
This case study in the professional education of engineers is based on a Talent Programme at Combitech in Sweden, in association with the Royal Institute of Technology. The approach is based on use of the Dialogue Seminar Method.
\end{abstract}

Keywords Dialogue - Education · Engineers ·

Tacit knowledge

\section{Introduction}

AI \& Society has often addressed the issue of engineering knowledge, which involves more than simply technical proficiency.

During an engineer's education, and later in his/her profession, he/she is trained in technology and how to rely on it. That is the way the education is formed, and it influences how engineering organisations value their new recruits. Still, after many years of practice, the engineer gradually learns, the hard way, that there are other things than technical brilliance that count; or, perhaps, it is the other way around, that the hardships involved in engineering projects are not so much about technology as they are about human interaction: an area that engineers are not specifically trained in.

The authors have designed and implemented a development programme for young engineers at Combitech, a Swedish consultancy company, as an introduction to the engineering profession. The Talent Programme was

G. Backlund $(\bowtie) \cdot$ J. Sjunnesson

Combitech $\mathrm{AB}$, Universitetsvägen 14,

58330 Linköping, Sweden

e-mail: Goran.Backlund@combitech.se tailored from the earlier programme Experience Development for Project Managers, which in turn is a result of the authors' earlier research. It is subdivided into three different areas; Technology, People Skills and Knowledge Development. The focus of the programme is to shed some light on important situations and conditions for an engineer, regardless of the specific technical task, thus making the young engineer aware not only of pitfalls but also of opportunities. So, we study the engineer's own experience in order to gain a better understanding of the professional environment he/she is working in. The Dialogue Seminar Method is fully used in the Experience Development Programme and has been adapted to the Talent Programme. It is a research method developed by the Royal Institute of Technology.

The Talent Programme lasts for $2+$ years for the participant, and up until now, four groups of engineers have been examined from the programme. The result of the programmes has been studied, and it can be observed that the young engineers value the programme and can clearly see how it has improved their skill and professional judgement.

We direct the young engineer's attentions towards areas that we know from experience are important in order to accomplish the mission. Now, after almost 3 years with the Talent Programme, we can see that we have equipped a group of new engineers with the insight that learning is key. These engineers are trained to reflect on difficult situations, to coach a colleague and also be coached, all on a regular basis. The programme trains them to be open to new perspectives, and as a consequence, they exert pressure on our organisation from below: 'we understand our situation better now and we want to learn more'. The true learning organisation is orchestrated from the roots. The mission of management is to teach people how to learn in 
their daily work. The Talent Programme is a training tool that initiates the life-long learning that complements the engineer's technical education.

\section{Development of technical systems}

Engineers coming out of university are trained in technical brilliance and are well prepared to understand how different technical systems work. After struggling in different development projects for some years, they will learn that technical ability is just a small part of the skill needed to be successful in practice. Professional cooperation is not something they have been trained for.

One of the main obstacles in developing new technology is being able to learn what the system is supposed to do and how it is supposed to do it. There is a common misunderstanding that this is solved with Requirement Specifications identifying the task of the system and Design Specifications visualising the solution. There seems to be a common belief that this information contains the knowledge needed to implement the system; that is often not the truth.

A Requirement Specification is, in the best of worlds, built up as a common understanding between the user and the supplier. When agreed and signed, two things happen simultaneously. The people in the development project start to work on a solution and build an image of the system based on how they understand the requirements. At the same time, the users continue the process of thinking. People do not stop thinking, just because specifications are ready and agreed. Two processes are working in parallel, mentally shaping the requirements. However, there is a good chance that these two processes will not arrive at the same conclusion. Even if the specification is stable, expectations on what the system is to achieve will develop in different directions.

The same kind of risk occurs whenever specifications are treated as the truth.

Many projects that fail do so due to misunderstood information, or misunderstandings between people, not due to technical limitations (Chaos Report 2009). So, the skill that for so many young engineers goes untrained is how to understand information and understand colleagues. Unfortunately, many people never recognise the importance of this area in the success of projects. Engineers are good at solving technical problems, but not always the right problems.

Another obstacle is the way we define cooperation. In processes, cooperation is often defined as two (welldefined) roles that interact. It resembles the way we define interaction for machines. We have two units passing information between each other in accordance with predefined rules. However, information is not knowledge, a person is neither a 'unit' nor a 'role', and interaction is not about passing information back and forth.

By being a consultant, this makes the area of understanding even more complex. As an employee of a systems development company, you will probably work with similar systems, getting used to the technology and methods used and becoming acquainted with your fellow engineers. But as a consultant, you must be prepared to move between different systems and different companies. Every time you switch task, you need to learn not only the new system but also how people work in the new company and how they cooperate. These two parts are inextricably linked: you need to learn your technical task, that is the tool environment, and how to interact with your human surroundings to be able to take responsibility for your assignment.

When schooling gives good training in technical skills, the industry needs to give training in human skills.

Think of your closest friends, those that you can be together with in silence and comfort, those who listen to what you say and know what you mean, those who are not afraid of disagreeing with you. You know what they feel, you feel what they think. That is empathy, the first half of cooperation. The second half is the ability to reconsider your own thinking: self-criticism. It is the ability to understand what a colleague says, and the ability to rethink your own standpoint, which is crucial in good cooperation. It has very little to do with processes, and it is not designed by technocrats. It is a human ability.

If the second half of us is technocratic, the first half is humanistic. Both develop with training.

\section{The Talent Programme}

The Talent Programme described here is an attempt to bridge the gap. The model for the Talent Programme is the programme called Experience Development for Project Managers (Backlund 2006). This programme was designed for experienced engineers in the project manager role. However, the target persons for the Talent Programme are recently graduated engineers, without any previous engineering experience. The purpose of such a programme is to accelerate the participants' learning and help them to become experienced faster.

The research on tacit knowledge is based on Professor Bo Göranzon's work since the 1980s (Göranzon 2009) that eventually established the research area Skill and Technology at the Royal Institute of Technology (KTH).

\subsection{Programme overview}

The programme consists of three blocks, as shown in Fig. 1. 


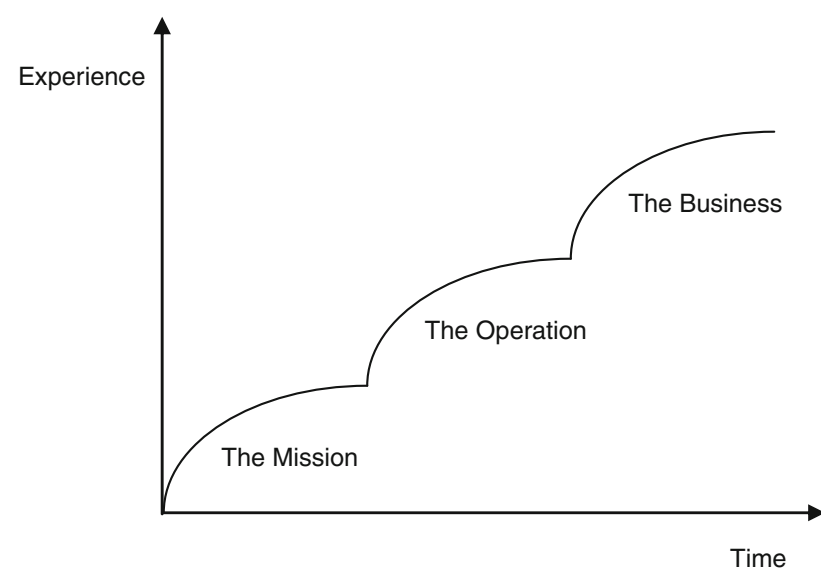

Fig. 1 The general focus areas of the Talent Programme

Our view is that experience grows as time passes by, but that it may grow faster with some facilitation. We first focus our attention on the mission that each participant has in their assignments in a customer organisation. The purpose is to learn that it is always your own responsibility to understand your mission and all the expectations that the customer organisation has of you; thus, making each participant more independent and driven by responsibility.

The next block widens the attention to cover the entire operation of the customer organisation and is not limited to the specific department where the participant has his/her assignment. The purpose is to shape an engineer who interacts effectively with all parts of the organisation, without fear.

Finally, in the last block, we direct our attention towards the business case of the customer operation, and we want the participant to understand the question: What really is the business case for the product that I am developing a part of? The purpose is to empower the participants to better use their professional judgement in everyday work, with a better understanding of the overall purpose of the product.

Furthermore, each block is divided into three different tracks: technical courses, people skills courses and a knowledge development seminar track; see Fig. 2.

The Technology track comprises traditional technical courses of two types: courses specific to the technologies chosen by the customer and technical courses of a more general type provided by Combitech. Examples of the latter type might be for a software engineer: Review Methods, Programming Languages, Software Testing Methods, etc.

The People Skills track offers traditional courses provided by Combitech, such as: Presentation Techniques, Rhetoric, Group Dynamics, Team Management, etc.

The Knowledge Development track is initiated by a pairwise interaction called Sparring, which is developed

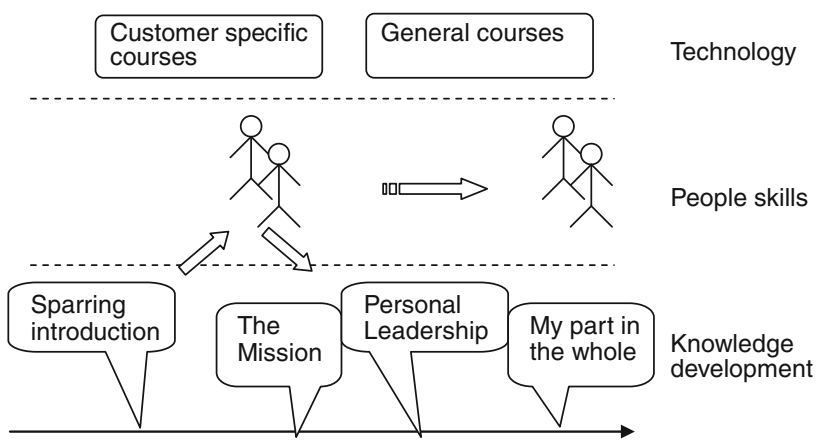

Fig. 2 The composition of the first block of the programme (the mission)

into Dual Coaching later in the programme. The rest of the Knowledge Development track is devoted to the Dialogue Seminar Method, with subjects chosen to make the participant aware of the existence of these issues/challenges. The first block shown in Fig. 1-The Mission-consists of three seminars in this track: The Mission, Personal Leadership and My part in the whole. The following block-The Operation - is composed in a similar way, and the seminars focus on: Processes, Roles and Meetings. In the last block-The Business-the seminars are: The Competent Customer, Customer Value and Double Loyalties.

The programme is concluded with a formal examination, based on re-reading all the texts a participant has written during the programme and writing an essay about their professional development during the programme.

\subsection{The components}

Apart from the traditional courses in the programme, which are not further described here, we now focus on the unique parts of the Talent Programme.

\subsubsection{Sparring}

Sparring is really the first step towards Dual Coaching, which in turn is inspired by the management literature. Sparring is simply a way of making room for a brief moment of reflection in everyday work, together with a colleague rather than alone.

The participants are paired together in such a way to ensure that they do not share the working environment and can consequently ask better questions. The method is simple:

- A 1-h meeting on a regular basis, typically every 2-3 weeks.

- One participant questions the other for half of the time, and then, the roles are reversed.

- They ask each other open questions about their working situation. 
- If the colleague cannot answer a specific question, this indicates that they should investigate and the next time provide an answer.

As a guide, the participants are given a set of questions to use during a Sparring meeting. Typical questions for the subject The Mission would be:

- How do you know that you have rightly understood your mission?

- Who will use the results of your work, and what are their expectations?

- Which other persons are important for you to be able to complete your work, and how will you build a relationship with them?

Usually, each Sparring couple learns to ask the appropriate questions and gradually disregards the provided questions.

\subsubsection{Dual Coaching}

This is peer coaching, taken up a level from the Sparring concept, to meet the regular components of coaching well known in literature. Dual Coaching is based on the GROW model (Goals, Reality, Options, Will, see Whitmore 2009), which is essentially about setting personal goals related to your assignment.

Both Sparring and Dual Coaching are meant to be tools to help each other to see better; to realise the context and to realise what you have not yet learned. In your meeting with a colleague who asks questions, you are forced to formulate yourself - and in the process, you usually gain new insight. With these tools, we aim to train the participants to lead their colleagues and to be led by them, in search of a better understanding of the work context. In this way, we make this quest a natural part of everyday engineering work, a habit.

\subsubsection{The Dialogue Seminar Method}

The Dialogue Seminar Method has been developed in research together with the Royal Institute of Technology (Stockholm, Sweden). In brief, the method consists of the following steps (Backlund 2006):

- A subject is defined, and literature is found related to the subject.

- Every participant reads the literature, noting down any reflections inspired by the reading, e.g. events or experiences that come to mind while reading.

- The participants write an essay (a reflective story), based on one of the experiences brought-up by the reading.

- Dialogue seminar day: a group of persons meet to learn by reading their stories, one at a time, followed by a collective dialogue. Questions arise, metaphors and concepts are formulated to pinpoint insights.

- Seminar minutes are written, capturing the essence of the collective dialogue and the findings.

The method is a way of investigating experiences, individually and collectively. The form of writing a story is inspired by the essay, first described by the French philosopher de Montaigne (1580). The essence is to critically review your own experiences, through not only the writing process itself but also by presenting it to others.

\subsubsection{The guests}

In the first block of the programme, the group only meets its leaders during the seminars. In the second block, we bring in a guest during every seminar-an experienced person who presents one or two of their own experiences, related to the subject, e.g. Meetings. This is an opportunity to listen to the experiences and reflections of a senior colleague and to talk to them. In the last block, we invite guests from customer organisations, where the young engineers have their assignments, in the same way as in the second block. This adds some new insight into the history and collective experiences of that organisation. The purpose of bringing in guests is to provide the young engineers with new perspectives and an opportunity to reflect on experiences together with senior engineers.

\subsubsection{The examination}

The examination consists of two parts; preparation and opposition. The preparation part contains the following steps:

- The participant reads all of his/her previously written stories throughout the programme, noting down any changes in his/her own insights and findings, i.e. how you have developed during the programme.

- The participant writes an essay describing his/her learning journey throughout the programme: 'What I can now see that I have learned'. The participant is asked to elaborate on his/her findings.

- The participants are paired together, with the task of giving opposition to their partner's essay, in written form.

The opposition is executed with the entire group through the following steps (every participant has read the essays of all participants):

- The opponent reads his/her written opposition.

- The respondent gives immediate comments.

- A dialogue between the opponent and respondent takes place surrounding the topics in the essay, and the 
opponent's objective is to help the respondent to gain an even better understanding.

The examination is highly valued by the participants, because it is here that all the pieces come together and they gain a better understanding of the results of the Talent Programme. It becomes clear what they have learned and how they have developed.

The examination is supervised by Professor Bo Göranzon from the Department of Skill and Technology at The Royal Institute of Technology.

\section{Skills required by the leaders}

The Talent Programme is not a simple recipe for immediate success; specific skills are required by the leaders. You are asking young engineers to see the essentials of their mission and the context in which they are working. Most of them have no or few references to the professional world, and they are all confused about what is expected of them in their first assignment.

As a leader, you must find where the participants are and help them formulate what they see. It is not about analysing their situation and telling them 'the truth'. They must find it out by themselves. So, the challenge is to help each and every one of them to briefly step away from their daily work and to reflect on what they see. By reading essays from experienced consultants and writing essays about what you see, you are forced to take a step back and see what context you are part of. In the dialogues, your essay is highlighted by others adding more perspectives to what you see. It is intense training for the participants to put words on their working task in a foreign context. In that way, they learn to see what is essential.

For a leader, it starts with listening. You must understand what the person is trying to say in his/her essay and about the working situation behind it. To be able to understand it well enough, you have to listen to what is said both in the essay and in the dialogue. If the essay is not sufficient in order to pursue a good dialogue, you need to ask for practical examples until a story from real life is offered. You have to manage the dialogue in such a way that the participants' different perspectives add value to the story being told, so that both the story teller and the others learn from it. As a leader, it is your job to ensure that the dialogue has the quality needed to achieve this. You have to keep the participants focused on what gives value and avoid a common talking session without dominating it. You need to create a climate in the group that encourages questions and reflection. As soon as you start to dominate, the participants will hesitate in presenting their thoughts: they become quiet. The dialogue is used to shed light on something that is difficult to see, and if the participants stop trying, it will soon fail.

It is all about being curious to listen, you must want to know. Intensive listening will help you draw parallels with your own experiences, showing you what parts of the story need attention. That is the key to a balanced leadership. Listening also shows respect for the participants and what they say. Mutual respect is essential for people to gain the confidence needed to be able to open up about experiences that sometimes feel awkward.

When you hear and understand what a participant is trying to visualise, you have a few tools to work with: questions, dialogue and your own experiences. You can ask questions to which answers might lead to insights, you can ask someone in the group to comment and then let the dialogue continue as long as it adds value. You can also add your own experiences by telling stories from your professional life.

\section{Observable results and conclusions}

The examination forces the participant to be retrospective on the programme: What have I learned?

The method of analysing the results of the Talent Programme is to study the examination essays written by the participants and also interviewing a Project Manager who has worked close to several of the participants for her views on how they have developed. So far, we have concluded programmes with a total number of 16 participants. Other programmes are currently ongoing. When reading the essays, we particularly look for the participants' documentation of their own insights and learning.

Participants developed differently. Some participants found it easier to understand and adapt to the complexity of human cooperation than others. There is, however, a common understanding of the importance of it, but the ability to express and manage it in real life differs. What is presented here is a summary of the insights gained from the programme. The referenced quotes are taken from direct feedback from the young engineers, as well as from their examination essays.

\subsection{Improved confidence}

Everyone discovered that the uncomfortable feeling of stupidity, that occurs whenever there is something you do not understand, was shared by the rest of the group. This came as a relief to most of the participants, having 
received their assignments with no clue of how to solve them. It is not stupid to state that you do not understand, and it is not stupid to ask. This little insight is a key to learning. When you feel comfortable about asking, you are in a much better position to investigate whatever you need to know. ${ }^{1}$

\subsection{Developed awareness}

Another common insight is that when you start your first job, you think that the real challenge is solving technical problems. A few steps into the programme and you realise that there is another challenge: human cooperation. At the end of the programme, you realise how important and how difficult it is. You could say that we have complicated professional life for those young engineers, and thereby helped them to see what is essential, and deal with it. ${ }^{2}$

\subsection{Ability to reflect}

During the programme, the participants have written nine essays, each with different perspectives on their assignments. Each essay was investigated in Dialogue Seminars. At the same time, they have been assisting each other in the Sparring and Dual Coaching programmes. In this way, they are trained in how to express many of the complexities of their work and its context, and how to listen to and understand their fellow colleagues. Time and time again they have taken a step back to reflect on their work, which means that they have learnt another skill; the ability to see oneself in professional action. This ability is key to future learning. If you see your current assignment as training for

\footnotetext{
${ }^{1}$ I completely thought it was only me who felt like a fake, therefore the first CTP seminar came as a relief. It appeared that my Combitech colleagues/.../also felt like fakes on their first assignments.

... I have considerably more belief in my own competence, which means that I dare to take the steps that are required in order to get closer to what I'm striving to achieve.

2 If I look back over my first texts, I can see that the basic parts of my professional personality have not particularly changed during the journey that has been the CTP. However, I now have a better idea about what I'm doing and why I'm doing it.

We work with technical problems and solutions, we work with modes of operation and methods and we work within organisations and companies of various sizes and scope, but above all, with work with, for and alongside other people./.../Most of us, for example, can learn a programming language without any problems, but if we cannot understand what the customer wants, our technical skills won't make any difference.

Simply being technically focused doesn't work. Behind every product there are many people with their own wills, needs, different ways of thinking, etc. Working with people wasn't exactly what I thought the job would involve.
}

the next assignment, you will most certainly learn more and mature quicker (Sjunnesson 2007). ${ }^{3}$

\subsection{Taking responsibility}

Many of the participants have developed a strong sense of taking responsibility for their assignments. When something is unclear, they do not hesitate to do what is necessary to clarify it. The barrier you can experience when asking someone you do not know, or even when calling a person in another country, has been lowered; overcoming the barrier to asking questions, the will to learn and the will to influence your assignment increase. You could say that curiosity and ambition develops. Asking questions becomes a skill that is used for finding your role, learning your assignment, understanding your colleagues and gaining a holistic view of the context you are working in. It becomes part of your personal leadership.

This reflection is mainly based on observations on how some of the participants act in their current assignments, not so much on what they said in their examination essays. ${ }^{4}$

\subsection{Learning to learn}

The examination has been an eye-opener for many participants. In the search for how they have developed during the programme, they discover not only what they have learned during the programme but also see the effect of using reflection in daily work. They learned why they do as they do, and they learned how they learn. ${ }^{5}$

\footnotetext{
${ }^{3}$ It is in the dialogue that you can create an opinion about the background and the extent of a problem.

I've been forced to reflect on what I work with, who I work with and where I fit into all this. By listening to other people's experiences, problems and success stories has meant that I appreciate, value and understand the people around me better. It also makes me realise time and time again how difficult everything is.

... Sparring has worked as a way of reflecting through dialogue ...

It's probably where CTP invests most of its time: the art of reflecting and analysing one's communication.

4 In my own little world, "doing a good job" is not about solving the tasks you are given. In my opinion, it is about doing your job, pure and simple. Doing exactly what we are given is the least that can be expected of us. Doing a really good job is something more. I feel a strong loyalty towards those people that I work with and towards the tasks I have on my table. This means that a personal commitment to the task is built up and, from this, hard work follows.

I must learn to use existing processes better and to benefit from and adapt myself to them instead of feeling "put in place" by the fact that someone has decided what I should do. And I must accept that all processes are not optimal from my point of view, but may be from the point of view of others.

5 I've gained more experiences than I've actually experienced.

I've also learnt that by listening to other people's stories I can substantiate and draw experiences from my own experiences. Thereby, I can gain insights that without reflection would otherwise have passed by unnoticed or perhaps been lost by the wayside.
} 


\section{Discussion and method}

This is a qualitative study of the professional development of a group of individuals: young engineers. As a consequence, we cannot use a reference group, since this would be made up of other individuals, thus invalidating any comparative conclusions; nor is it possible to study the same group of individuals with and without the Talent Programme, for obvious reasons.

However, we have studied the examination essays from every participant of the Talent Programme, and we also have an evaluation made by a Project Manager in close working relations with many of them.

One can argue that the most credible assessment of the effects of the Talent Programme can be made by the participants themselves. In fact, they can make a more valid statement of the effects than the designers of the Talent Programme. After all, who else can make a more valid statement about the results?
Open Access This article is distributed under the terms of the Creative Commons Attribution Noncommercial License which permits any noncommercial use, distribution, and reproduction in any medium, provided the original author(s) and source are credited.

\section{References}

Backlund G (2006) On tacit skills in engineering ( $\mathrm{Sw}$; Om Ungefärligheten I Ingenjörsarbete). Royal Institute of Technology $(\mathrm{KTH}), \mathrm{PhD}$ thesis

de Montaigne M (original ed 1580, 1993) The complete essays. Penguin Books

Göranzon B (2009) The practical intellect (Sw; Det praktiska Intellektet), Santérus

Sjunnesson J (2007) Experience and processes, (Sw; Erfarenhet och Processer). Royal Institute of Technology (KTH). PhD thesis

The CHAOS Report. Standish Group International Inc., 2009

Whitmore J (2009) Coaching for performance, Nicholas Brealey Publishing, London 